The use of historical data in rule-based modelling for scenarios to improve resilience within the building stock

Flora Roumpani ${ }^{\text {a* }}$ Polly Hudson ${ }^{\alpha}$ Andrew-Hudson Smith ${ }^{\alpha}$

${ }^{a}$ The Centre for Advanced Spatial Analysis, UCL, London, UK;

*f.roumpani@ucl.ac.uk 


\section{The use of rule-based modelling and historical data for scenarios to improve resilience within the building stock}

Digital documentation has become integral to the preservation, analysis and communication of historical sites. New platforms are now being developed that involve complex 3D models and allow the analysis of spatial data. These include procedural modelling, a technique that enables the rapid development of 'dynamic' 3D environments, and generation of simulations for entire cities, resulting in low cost, high resolution 3D city models. Though procedural modelling has been used in the context of archaeology to 'recreate' cities at specific historic time points, the use of historical data in the development of rule-based procedural models for current cities has been little explored. Here, we test the extent to which construction age data, historical building regulations and architectural knowledge can be used in the generation of procedural rules, and the level of detail and potential impact that these models may have. Rather than creating an accurate representation of the city, we instead seek to simulate the way in which urban areas are likely to behave under certain conditions, in order to test what-if? planning scenarios. This allows us to explore more flexible ways of digitally 'creating' cities, past and present, and to gain insights into underlying 'rules' that govern their physical form.

Keywords: procedural modeling; building age data; scenarios; CityEngine; Camden; City modelling; Victorian house.

\section{Introduction}

"We can build Rome in a day" says the director of the Centre for Advanced Spatial Analysis Andrew Hudson-Smith, in a discussion about improving planning in London (Taylor, 2014). Today, widely available city modelling applications let us 'virtually' reconstruct, within hours, using 3D scanning and modelling. This also allows for these models to be held on indefinitely via digital storage. The generated 3D models can then be enhanced with various types of information in order to be used for the effective 
management of the historic environment (Kalay et al., 2007), and then in visualisations for communication with the broader public (Hudson-Smith et al., 2007).

However, though $3 \mathrm{D}$ modelling has proven to be an effective tool for the documentation of heritage sites, historic cities are never static. As noted in the 2011 UNESCO Historic Urban Landscape (HUL) Recommendations (UNESCO, 2011), cities are dynamic entities, laboratories of creativity, stimulated by their specific cultural historic landscapes. Cities should be viewed as dynamic adaptive systems that evolve over time (Batty, 1971), while still maintaining their identity (UNESCO World Heritage, 2013).

Mature cities today face many challenges. Climate change, urban transformation driven by population growth and technological advancement, gentrification and new development, all press for change. At the same time, one of the areas of greatest energy saving potential within cities has been identified as the systematic renovation of older stock and its reuse (BPIE, 2011, p. 7, 2011). As such the need to better understand the economic, environmental and socio-economic impact of specific types and ages of buildings, to inform decisions on retention and demolition, becomes ever more critical as does the identification of opportunities and dangers associated with radical interventions into the urban fabric.

To creatively integrate preserved heritage and new developments, from a dynamic point of view, required new tools, methods and approaches for modelling and planning complex and dynamic urban systems. These are needed to capture the dynamic character of the city and have the potential to help improve efficiency in the management of the historic fabric. A significant advantage of being able to model the city in this way, is that it enables the past to be linked with the present and for a more holistic view of the urban environment to be achieved, in order to aid in the development of appropriate 
conservation strategies in planning.

In the next paragraphs we use a specific approach to modelling the city, known as procedural modeling. This method allows the effective generation of $3 \mathrm{D}$ cities with a click of a mouse, and the integration of data feeds and analytical tools, enabling dynamic 3D models to be developed. Used in combination with age data and architectural knowledge these offer a new approach to the production of conservation scenarios at neighbourhood and city level.

\section{Procedural Modeling and Tools}

Procedural modeling is a method used in computer science to create geometries from a set of rules. Pascal Muller, a researcher from ETH Zurich, used this technique in 2008 to develop CityEngine, a software application specifically designed for building 3D urban environments. Applying this technique to the urban context has allowed for the development of complex rule-based models and the automatic and near-instant generation of 3D cities (Müller et al., 2006; Parish and Müller, 2001). Fully dynamic 3D scenes can be produced, instantly edited using simple controls, such as sliders and switches. This characteristic, makes CityEngine ideal for its use in urban planning for the development of urban planning scenarios, and within the movie industry for the development of high resolution city 3D models, but is also an ideal approach for the digital recreation of past city environments, through the use of historic records and maps.

CityEngine has already been used in the context of the historical development of cities, with one of the early examples being the "RomeReborn 2.0" (Dylla et al., 2008). The project involved the generation of a 3D procedural model of Rome in $320 \mathrm{AD}$ and it was described in 2008 as 'the largest virtual reconstruction, cultural heritage, and digital archaeology project to date' (Ref http://www.esri.com/software/cityengine/ 
industries/rome-reborn). In this project a plaster model of the city of Rome, held by the Museum of Roman Civilization, was scanned under the direction of IATH, University of Virginia and the Politecnico di Milano. The data were then imported into the CityEngine software where the development of 'grammar rules' for the buildings was overseen by archaeologists. This resulted in the generation of over 7000 3D building models, able to be exported into any 3D package or visualization software. The project opened 'new channels for education, for collaboration between scholars, and for the communication of archaeology to the general public' (ibid).

In the next section, we will demonstrate how City Engine is used to procedurally model a specific building typology, and the way in which historical knowledge of the built fabric is essential to this process. Here we select the mid Victorian house. We test the method within the London Borough of Camden and use building age data to identify the locations of current Victorian domestic stock. Through this process we develop a system which allows all mid Victorian buildings in Camden, to be procedurally generated. This results in an adjustable and updatable database of 3D buildings of the specific typology.

This method is then the first step of looking at protected assets within the wider context of the contemporary City and use the rule-based design to produce scenarios that refer to the conservation of the built environment. This will demonstrate why tools such as procedural modeling may be ideal for understanding the city via the HUL approach. Here we begin with the Victorian house, but this method can be used in other typologies to produce a truly responsive model of London.

\section{The Victorian house}

In the UK, as in most European countries, buildings are subject to building 
regulations. These provide guidelines that determine certain aspects of a building's design. Historically building regulations were also drawn up by central government to guide towns in the formulation of their own building 'bye' laws (Harper, 1985). Where regulations are 'deterministic', that is where they are detailed enough to determine an identifiable building type, the potential exists to produce rules that replicate the building typologies' form.

Here we look specifically at the one of London's most iconic typologies, the Victorian house. "This building morphology makes London unlike any other city, particularly in its square terrace formation (460 squares in London by 1900)" (Forshaw and Bergström, 1986, p. 46). In Figure 1 we see an example of terraced houses within the urban fabric, recreated using GIS.

In this study we break down the form of the Victorian building into its main properties and provide a step-by-step example of how building regulations relating to the Victorian house can be used in the generation of rules for 3D procedural models. We show how construction age data, building footprint information and local area analytics for the urban area can be used to reproduce building form.

The Victorian house (Figure 2) is principal residential building typology of Victorian era, which spanned from 1837 to 1901 . Assisted by the industrial revolution, these years saw a rapid increase in the population of the UK, doubling its size between 1801 and 1851 (Crafts, 1985). Population growth drove the construction of millions of speculatively built houses during the period, now a defining feature of London and other UK cities, and with such rapid expansion came new Building Acts.

A major game changer in the shaping of building regulations during the Victorian period was the cholera outbreak, in 1831 (McLean, 2005) which occurred just before the 
beginning of Victoria's reign. This led to a Committee being established to reconsider the 'regulation of Buildings and Improvement of Boroughs' leading to the "State of Large Towns and populous Districts" Act in 1844 and 1845 with its emphasis on health reforms. An important section of the regulations controlled the dark and unventilated spaces of cellars, and gave guidance for back to back housing which to a large extent defined the morphology of the Victorian blocks. "Cellar dwellings houses enclosed courts and backto-back dwellings were to be controlled and a space was now to be provided in front and behind houses related to their height..." (Harper, 1985, p. xiii). These rules gave rise to identical row houses with slate rooftops and with a private front and back yard. Their design was promoted in several ways across the country, with "The Builder", a popular industry journal, offering instructions on how to build new housing and acting as an effective medium for distributing information and replicating standardised designs. The Victorian terrace thus evolved a mass-produced design to accommodate rapid population growth (Allen et al., 2011).

Despite their mass production and the standardised reproduction of specific features, Victorian houses also incorporate a range of architectural styles. Early Victorian houses in London for example, i.e. those built in the late 1830s and 1840s were in large part influenced by the classicism of Georgian architecture while by the 1850's Italianate style and Gothic became fashionable with bay windows and grey slate becoming prominent features. The size of the Victorian house also varied considerably. Victorian houses for the middle classes for instance, had extra rooms to accommodate servants (Muthesius, 1982)(Marshall and Willox, 1986).

However specific characteristics can be identified that if combined they make the majority of mid Victorian houses identifiable, unique and reproducible. These include bay windows, brick bonding methods, pitched slate roofs, sash windows, terraced form, 
fireplaces and chimneybreasts in every room, front area back and front (Marshall and Willox, 1986).

These formal elements that in large part derive from regulations not only gave guidance to developers but essentially provide some ingredients of a 'recipe' for building the Victorian house. In the next paragraphs, we will explain how we use a recipe to develop the procedural model, and demonstrate the methodology for integrating planning regulations in procedural modeling visualization.

\section{Building the Victorian House in CityEngine}

Building regulations provide minimum standards for design, construction and alterations. The 1875 Public Health Act imposed a front entrance yard in each Victorian house and required the terraced houses to have their own privy, with rear access to allow the "night soil" to be collected. The height and width of the building also correlated with street width in order to ensure access to light.

In CityEngine we create Computer Generated Architecture (CGA) rules to include front yards as setbacks relative to the street width, using a standard setback function to define the main body of the house. We can then define the width of the setback as a property, with varying depth. The rule will rewrite the plot with two shapes, a main volume and a setback with varying width. This can be translated to the following procedural string:

Lot $\rightarrow$ Setback

We can then create a parcel that consists of two housing units, one a mirror of the other, using a split function. The split function is used to create the two mirrored volumes, 
the main house and the back garden. We can then add an option of the buildings to either be generated as mirrored or sequential. By rule of thumb, the utilities and kitchen of the Victorian house is found in the back of the extension, while the main living room is located in the front in the main body of the building. The house is then separated to the main body and the extension in the back. The string that generates this process would then be:

Lot $\rightarrow$ Setback, (Main $\rightarrow$ Garden, (House1,House2) $\rightarrow$ Extension)

The model by Law 54, presented 4 variations of the Victorian house correlating plot width with height of the house and the presence of extensions (Figure 3). The bigger the house, the larger the open space at the back of the house. Moreover, there are indications about the width of the house and the L-shaped design of the footprint. Extensions take up to $50 \%$ of the back yard in width to allow light to go into the main building and air to circulate through the building. The extension can then be optional.

Rooftops are moreover typically shed, tilted to the side, in order to seemingly connect to the attached building. Each row of houses has identical roofs in terms of height and angle. The mirrored approach allows the buildings to use the same pipes for their fireplaces and avoid chimneys in the middle of the pair. In this stage, two subsets need to be developed as:

Lot $\rightarrow$ Setback, (Main $\rightarrow$ Garden, (House1, House2) $\rightarrow($ Extension $\rightarrow$ Garden $)) \rightarrow$ Rooftops

The façade can be generated as a separate object, by splitting the house by the number of floors. In this case ground floor, and upper floors, whose number is defined by the floor height and building height. The integration of the façade as a separate object would require an integration of a second axiom i.e. the axiom "Façade". The same technique can be used to define the tiles for the window bay and the door. While windows 
can repeat in the $\mathrm{x}$ and $\mathrm{y}$ axis. A simple translate function can be used to create insets for windows and doors. The bay can either be inserted as an external object, or created using shed objects. The complete sequence to create a schematic representation of the mirrored detached Victorian house is then the following:

Lot $\rightarrow$ Setback, (Main $\rightarrow$ Garden, (House1,House2) $\rightarrow$ (Façade $\rightarrow$ Floors $\rightarrow$ (Tiles $\rightarrow$ Windows , Doors, Bay $)) \rightarrow($ Extension $\rightarrow$ Garden $)) \rightarrow$ Rooftops

This step-by-step process is shown in Figure 4 and was aimed at demonstrating how building regulations can be used in combination with CGA rulesets to generate procedural building typologies. The ruleset can then be applied to multiple shapes or areas, creating the iconic row houses (Figure 5).

One of the main aspects of this work is that this method creates variations and not clones, which allows the automatic reconfiguration of the generated building depending on different attributes. For example, it is possible to create a new variation by simply adjusting the height of the building without the need for re-modelling the house as a whole. The advantage of the procedural method, in comparison to a standard 3D modelling method, is then that the generated system can automatically produce such variations, by simply "tweaking" the values of the attributes in the system. This leads much faster building of flexible scenarios.

However, once a procedural typology is created, it is important to be consistent to each produced variation. We need a method in addition to the regulations presented above, to evaluate each and every generation in order to ensure consistency. For this, we implement a "Blueprint System". This was originally developed by Hello Games in the procedural game "No Mans's Sky" (2016) to evaluate the procedurally generated worlds of the game. The system outputs unlimited variations based on the produced rulesets by 
automatically modifying parameters and taking snapshots of each variation which are stored as images within a folder. Using these images we could identify permutations that would not be encountered in real life, such as the first column of the set of images presented in Figure 6. We then refine the design of the rules to exclude these cases from occurring in the generation process. E.g. Floor height of a Victorian house must range between $2.8 \mathrm{~m} .-5.5 \mathrm{~m}$ and a bay is between 35-66 angle, otherwise it should not exist.

Such capacities and thresholds can once again derive from regulations. For example, Knights Annotated Model Bye Laws, define dimensions of the main house and extension capabilities based on the plots dimensions. This generation of building types based on the plot they are in, creates a base for the automatic generation of 'What-if?' scenarios.

These features can then be integrated into the generative design and produce viable variations which are dependent on the type and size of parcel, and on other urban morphological features such as street width and distance from other buildings. Figure 7 showcases the Victorian ruleset variations on different parcels, building height and road width.

In this case study, building regulations are used as inputs to determine the generation of rules in the model. However, the geometry and fabric of each building will undergo significant changes during the course of its lifetime (e.g. extensions are very common in Victorian houses). This can be incorporated in the model, similarly to previous steps, but creating a separate branch of volumes which attach to the main geometry and create different extension variations.

As it is not the purpose of this study to create accurate building type morphologies, we now explore other uses of building age data in the production of dynamic scenarios. 


\section{Procedural visualization of Victorian Camden, London.}

The Borough of Camden contains a wide variety of architectural styles and building typologies from medieval to newly built structural expressionism. Characterization of the urban landscape and an understanding of the properties of its buildings, and particularly their age, forms a crucial part for identifying each building's typology. Here we used building attribute data on age, and land use on a building level in Camden, with the limitation that the data were still undergoing verification. This also allowed for the location of Victorian buildings over the entire Camden area to be identified, and for analytics to be produced for each parcel or zone. Procedural zones were defined within the study. Analytics were then developed for the minimum, maximum and average area of parcels, size of parcels, plot coverage, building height, number of buildings per zone and percentage of Victorian houses per procedurally generated zone. This allows parameters to be adjusted to correspond to each procedural zone, using a "tagging" methodology, which attaches the analytics to the zone within CityEngine.

The analytics are then used to define the number of zone subdivisions. These will form the procedural parcels, the percentage of procedural Victorian buildings per zone, the average size of building footprints and parcels, and the maximum and minimum height of buildings. In this way we can produce a system which, although it does not create a precise representation of the Victorian buildings in Camden, it does produce statistically accurate results. i.e will correctly determine the actual number of Victorian buildings within the plot and plot coverage. Figure 10 illustrates a comparison between static shapes and the results of this method for a Victorian block in Camden. This enables us to validate the results of this method. 
The mapped block in Camden illustrated in Figure 10-(a and c) are parcel polygons imported in CityEngine from the Land Use registry with extruded volumes using the Edina footprint and height data ${ }^{1}$. As in a standard GIS map, the imported geometries are static meaning that even though it is possible to change individual shapes by direct editing of the geometries, it is impossible to create a global rule or policy which would apply to a large area. In the scenario of Figure 10-(b), we used the road network from Open Street Map (OSM) to generate streets and pavements, and an integrated skeleton subdivision algorithm for the plots of the selected block. We then used analytics for the specific block, to adjust the number of subdivision and parcel and building footprint area. The Victorian rule set, described in the paragraphs above, is then integrated to generate a schematic representation of the block Figure 10 (b). We can then have an approximate visualization of the area, which produces the same statistics as the original data. And more specifically, the same number of houses, the same coverage per parcel or block (Figure 11).

We have used the same method to produce procedurally generated zones with Victorian buildings for the entire Camden borough, as shown in Figure 12. The application automatically recognises the locations identified as Victorian terraced houses and replaces extruded red volumes with the procedural Victorian ruleset as created in the previous paragraphs.

The usefulness of this method is that it can be used to create scenarios for large areas. For example, using the density slider, we can control the global percentage of Victorian houses in Camden. The series of images below, illustrate the percentage of Victorian buildings starting with $100 \%$ Victorian buildings to $-100 \%$, left to right. The percentage is added or subtracted to the already existing percentage of Victorian houses as formed from the analytics. Therefore, a $0 \%$ value corresponds to a $0 \%$ rate of change. A $-10 \%$ will decrease the global percentage of zones by $10 \%$ etc. 
The main challenge regarding the nature of the datasets, was the joining up of fragmented information. Spatially located building age data are essential for this type of study, though extremely difficult to access within the UK. Age data are of growing use in energy analysis, with sources ranging from government databases (Huuhka and Lahdensivu, 2016), statistical archive records (Aksözen et al., 2017) and historical maps (Tanikawa and Hashimoto, 2009), to remote sensing LIDAR surveys (Tooke et al., 2013). In countries such as the US, property tax valuation datasets, which include age information, are also now being released by many authorities as open data (NYC, 2017). However in the UK city wide age datasets are only available at building level from commercial sources (The GeoInformation Group, 2017), with the release of property tax data tightly controlled at this scale (VOA, 2017). As such painstaking, manual collection of age data was required for this study, drawing on specialist knowledge of building periods and the use of historical surveys (CHS, 2017; Pevsner and Cherry, 1998; Survey of London, 2016) and historical maps (Edina Digimap, 2018).

Current building footprints and building height data are available for the UK via EDINA Digimap. An online portal run by the University of Edinburgh for the distribution of geographic information relating to planning and the environment. Augmentation of this type if centralised database with additional parameters such as land-use, storeys, age and designation data, as well as wider access for planners, heritage specialists and other built environment professionals, would not only facilitate more rapid development of 3D models, but also promote more efficient management of the building stock.

Conclusions 
We have combined information on historical building regulatory frameworks and building age data to create procedural models of 19th century buildings and blocks. Initial tests have demonstrated that with careful consideration highly detailed models can be generated, reproducing not only building typologies, but also façades and potentially interior details as well, by using only age, footprint and building regulation data. Different typologies can be modelled from different periods of London's stock which is part of further work.

The result is a dynamic 3D city-model which has embedded information from planning regulations, to building age data. These applications have the potential to have a significant impact on urban heritage policy and practice as they present an integrated view of the preserved urban environment within future urban regeneration scenarios. These have a wide range of potential applications, and could be used to rapidly visualise at low cost, planning implications for proposed demolitions within historically sensitive urban sites, retrofit proposals for specific types of historic stock, or worst case scenarios for interventions such as altering height precedents..

The models also have potential applications for measuring different geometry related analytics, such as energy consumption, urban heat, and indoor pollution analysis, for which building geometries on which to base calculations, are required. Essential to this approach is an understanding that procedurally generated objects do not attempt to represent something accurately, but instead create an approximate representation of an object's form. This is important as the aim is not to accurately recreate a city, but to create a hypothetical city which behaves as the real one but into which 'What if?' scenarios can be tested. Improving access to knowledge, archive material and digital data relating to our past, and to the evolution of our cities and their building stocks forms an essential part of this process. It also allows for greater experimentation in the reconstruction of urban areas, 
increasing our understanding of the stock's dynamic behaviour and the long-term impact of decision-making regarding the retention or loss of buildings and streets. Above all, it highlights the importance of historical knowledge in developing sustainable urban development policies for the future. 
Bibliography

Aksözen, M., Hassler, U., Kohler, N., 2017. Reconstitution of the dynamics of an urban building stock. Building Research \& Information 45, pp. 239-258.

Allen, J., Okoro, T., Rosenfeld, O., 2011. Race, space and place: lessons from Sheffield. ACE: architecture, city and environment 6, pp. 245-292.

Batty, M., 1971. Modelling cities as dynamic systems. Nature p. 231, 425.

BPIE, 2011. Europe's buildings under the microscope. [online]. BPIE - Buildings Performance Institute Europe. [accessed 7June 2015]. Available at: http://bpie.eu/publication/europes-buildings-under-the-microscope/

CHS, 2017. Camden History Society Publications. [online]. Camden History Society. [accessed 22 Sept. 2017] Available at: http://www.camdenhistorysociety.org/quote/. Crafts, N.F., 1985. British economic growth during the industrial revolution. Oxford University Press: USA.

Dylla, K., Frischer, B., Müller, P., Ulmer, A., Haegler, S., 2008. Rome reborn 2.0: A case study of virtual city reconstruction using procedural modeling techniques. Computer Graphics World 16.

Edina Digimap, 2018. [online] Edina Digimap. [accessed 29 April 2018] Available at: https://digimap.edina.ac.uk/roam/historic.

Forshaw, A., Bergström, T., 1986. The Open Spaces of London. Allison \& Busby. Harper, R.H., 1985. Victorian building regulations. Mansell: London.

Hudson-Smith, A., Milton, R., Dearden, J., Batty, M., 2007. Virtual cities: Digital mirrors into a recursive world, UCL: London.

Kalay, Y., Kvan, T., Affleck, J., 2007. New heritage: New media and cultural heritage. Routledge.

Marshall, J., Willox, I., 1986. The Victorian House. Sidgwick \& Jackson. 
McLean, D., 2005. Public Health and Politics in the Age of Reform: cholera, the state and the Royal Navy in Victorian Britain. IB Tauris.

Müller, P., Wonka, P., Haegler, S., Ulmer, A., Van Gool, L., 2006. Procedural modeling of buildings, in: Acm Transactions On Graphics (Tog). ACM, pp. 614-623.

Muthesius, S., 1982. The English terraced house. Yale University Press: New Haven, CT.

NYC, 2017. PLUTO and MapPLUTO. [online] [accessed 25 Sept. 2017] Available at: https://www1.nyc.gov/site/planning/data-maps/open-data/dwn-pluto-mappluto.page.

Parish, Y.I., Müller, P., 2001. Procedural modeling of cities, in: Proceedings of the 28th Annual Conference on Computer Graphics and Interactive Techniques. ACM, pp. 301308.

Pevsner, N., Cherry, B., 1998. London 4: North (Pevsner Architectural Guides:

Buildings of England) (v. 4) - AbeBooks. Yale University Press.

Survey of London, 2016. South-East Marylebone. UCL. [online] [accessed 22 Sept 2017] Available at: https://www.ucl.ac.uk/bartlett/architecture/research/surveylondon/current-area-study-south-east-marylebone.

Tanikawa, H., Hashimoto, S., 2009. Urban stock over time: spatial material stock analysis using 4d-GIS. Building Research \& Information 37, 483-502. https://doi.org/10.1080/09613210903169394

Taylor, D., 2014. How could 3D city modelling improve planning in London? New London Quarterly.

The GeoInformation Group, 2017. The GeoInformation Group | UKBuildings. [online] [accessed 24 Sept. 2017]. Available at:

http://www.geoinformationgroup.co.uk/ukbuildings.

Tooke, T.R., Coops, N.C., Webster, J., 2013. Predicting building ages from LiDAR data with random forests for building energy modeling. Energy and Buildings 68, 603-610. https://doi.org/10.1016/j.enbuild.2013.10.004 
UNESCO, 2011. Recommendation on the Historic Urban Landscape, including a glossary of definitions. [online]. UNESCO. [accessed 2 May 2018] Available at: http://portal.unesco.org/en/ev.phpURL_ID=48857\&URL_DO=DO_TOPIC\&URL_SECTION=201.html.

UNESCO World Heritage, 2013. New life for historic cities: The historic urban landscape approach explained. [online]. UNESCO World Heritage Centre. [accessed 2 May 2018] Available at: http://whc.unesco.org/en/activities/727/.

VOA, 2017. Valuation Office Agency: Council Tax statistics - GOV.UK. [online] [accessed 22 Sept. 2017] Available at: https://www.gov.uk/government/collections/valuation-office-agency-council-taxstatistics. 


\section{FIGURES}

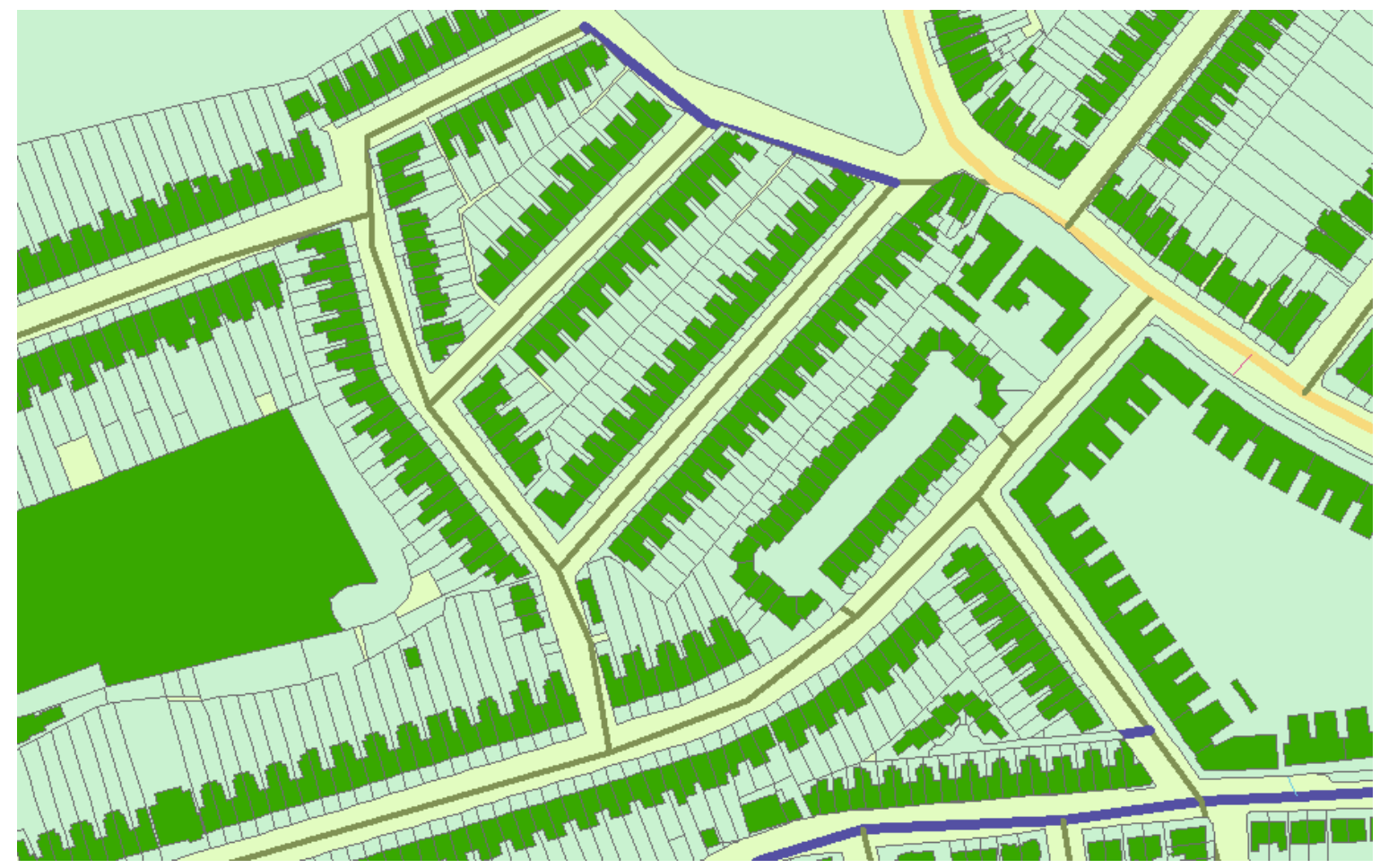

Figure 1. Rows of Victorian houses in Camden London. Reproduced courtesy of Ordnance Survey, OS MasterMap Topography Layer. OS MasterMap Topography Layer. 


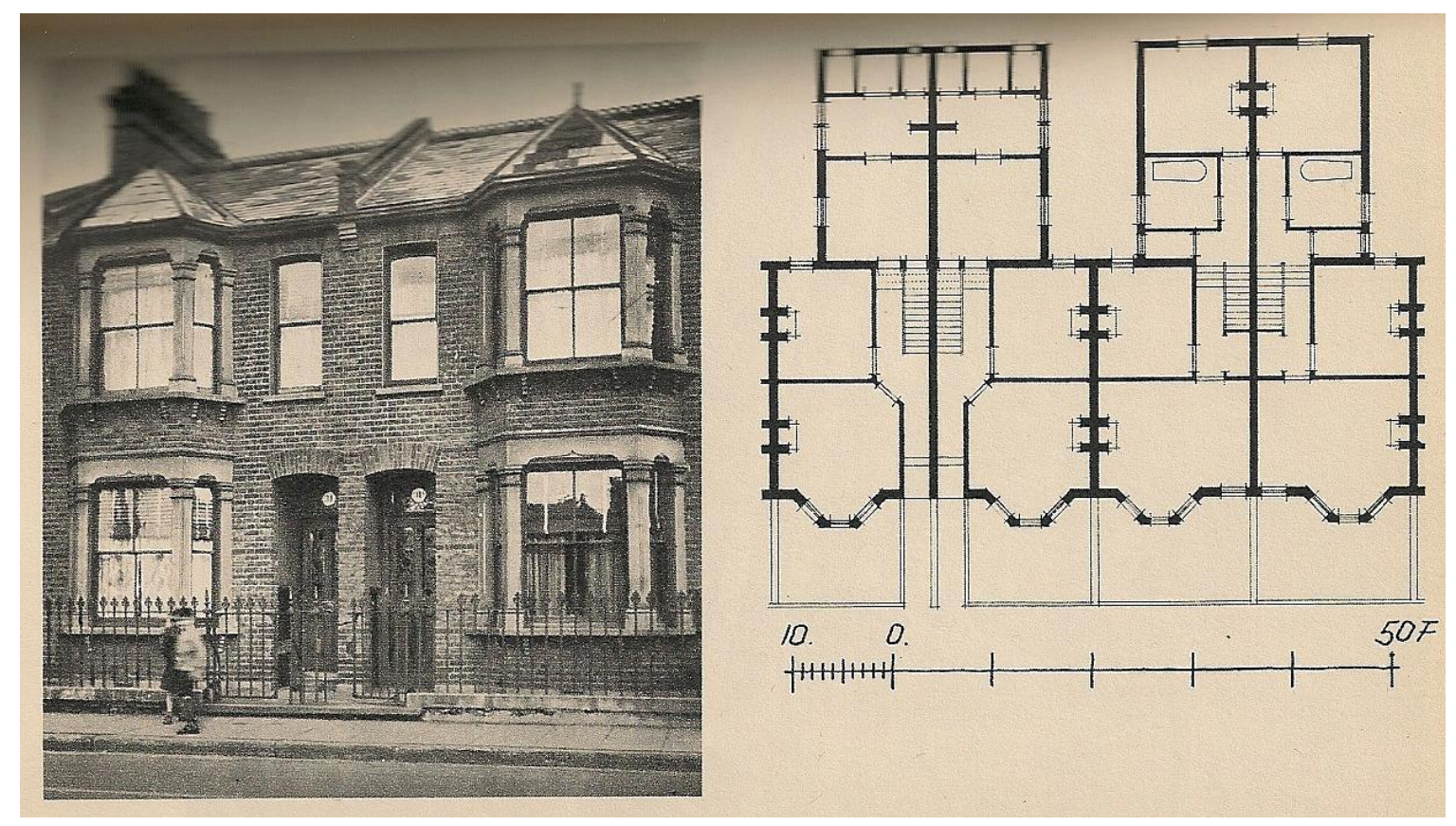

Figure 2. Typical Victorian house of the 1890s mostly build at the outskirts of London, for the low income families. Terraced or semi-detached, consists of two housing units, mirrored, cleverly designed so that they connect through their fireplaces to efficiently share chimneys with their neighbour (Marshall \& Willox, 1986). 


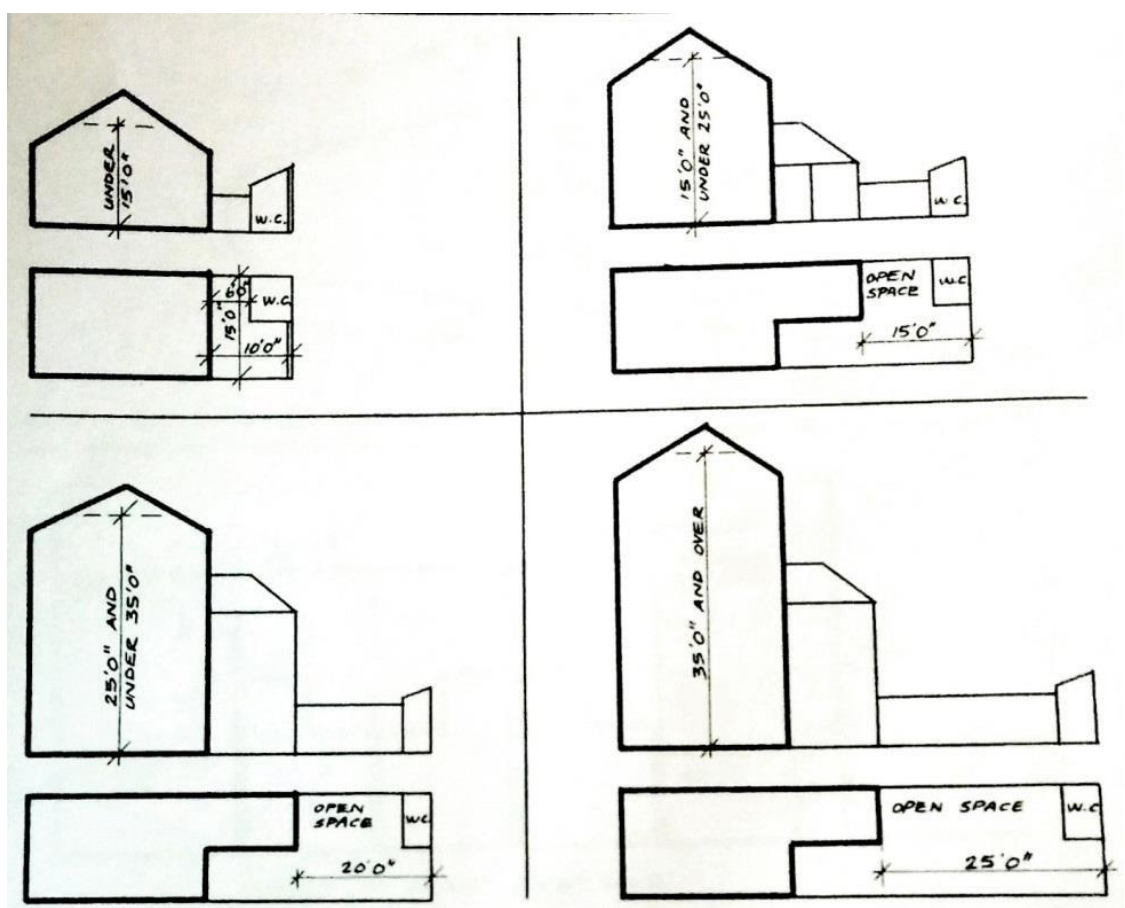

The standard condition covered by Model By-law 54, described on Table 8 , sheet 7 .

Figure 3. Variations for different plot sizes. One floor buildings tend to have smaller plots, while over two floor buildings typically have an extension at the back. Source: Model by law 54, table 8 sheet 7 found in Harper (1985: 64). 

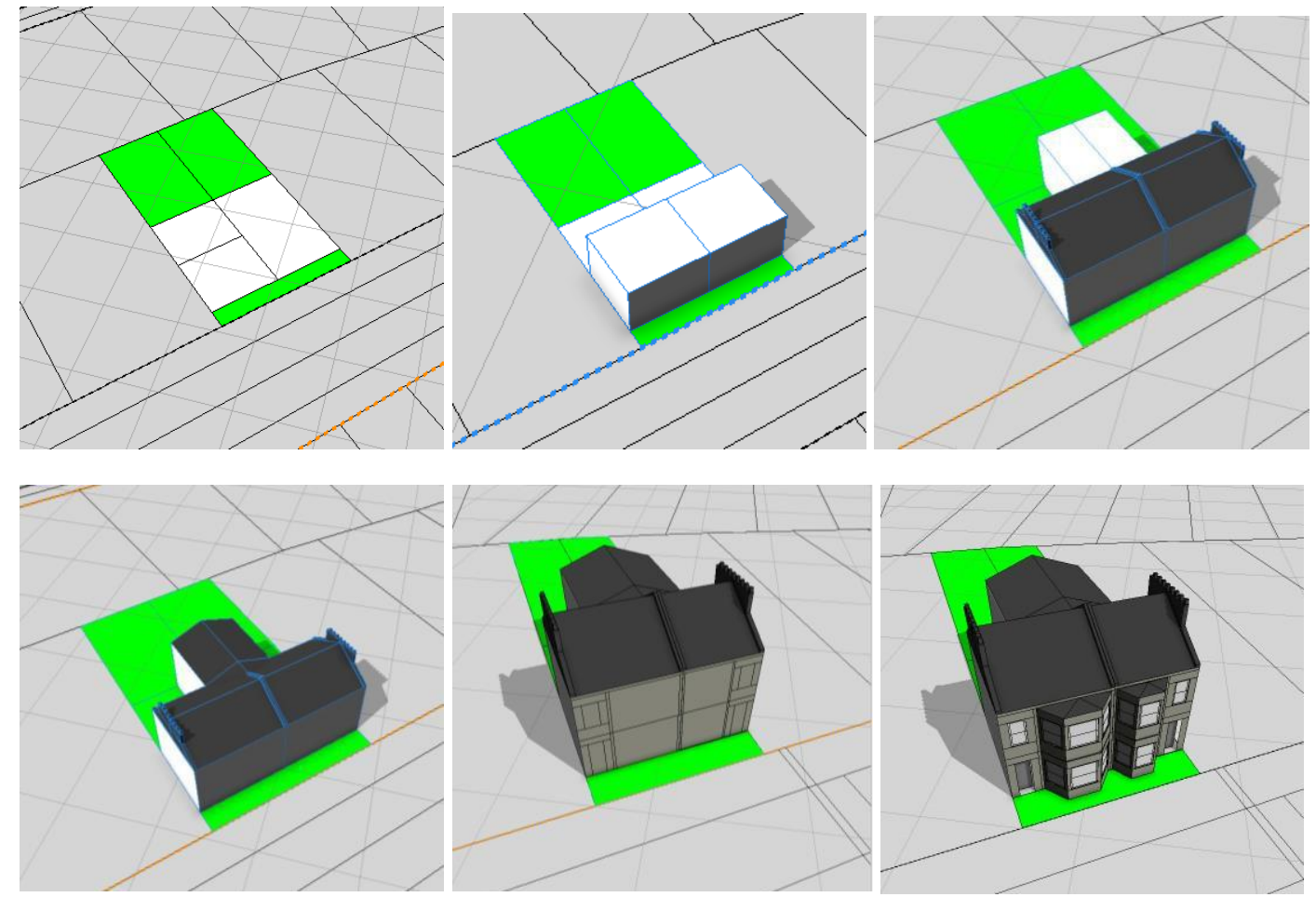

Figure 4. (a) Mirrored plots and setbacks generated. (b) The main volumes of the house. (c) Rooftops and optional extension in the back of the Victorian house. (d) Generation of rooftops and chimneys. (e) Rewriting the façade to generate windows and other morphological elements. (f) A schematic generation of a Victorian façade. CGA rules that yield elements of the façade such as the bay can be independent and can either be brought as separate objects or generated as a function. Copyright of the authors. 


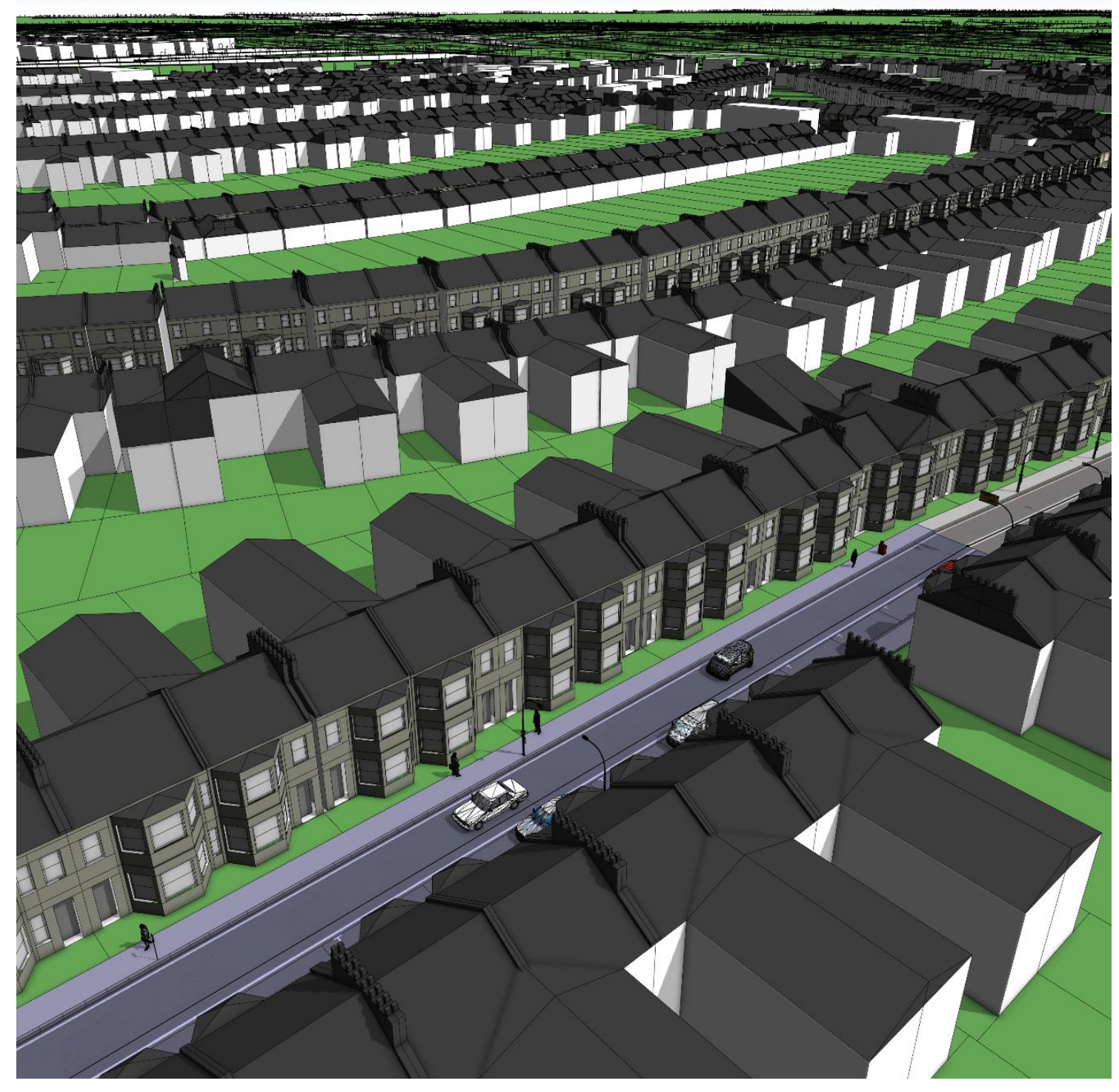

Figure 5. Procedurally generated rows of Victorian houses. Demonstration of the above CGA rule being applied on large areas. Copyright of the authors. 

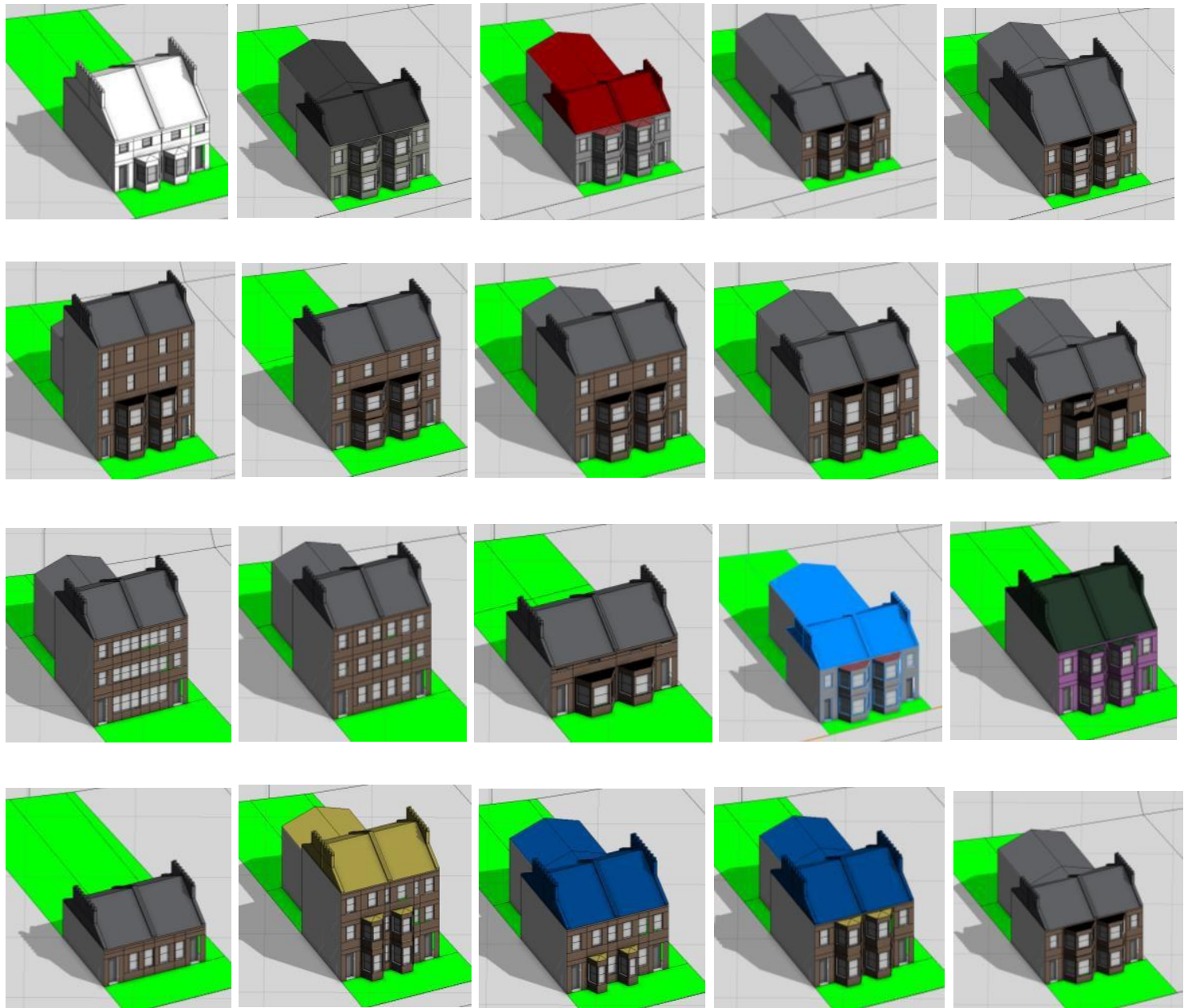

Figure 6. Permutations of a Victorian house automatically generated using a Blueprint method and screenshots. Copyright of the authors.
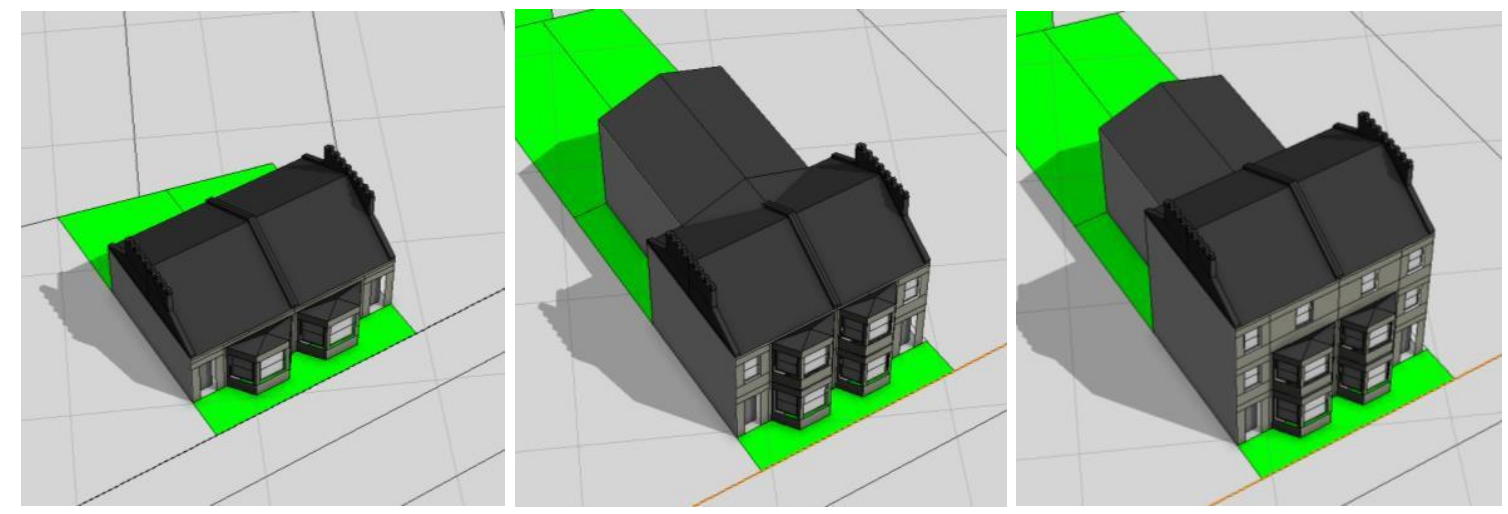

Figure 7. Procedural modeling generating accurate morphologies within the London Borough Camden using only building age, building regulations and building footprints, 3 variations scaling building height. Copyright of the authors. 


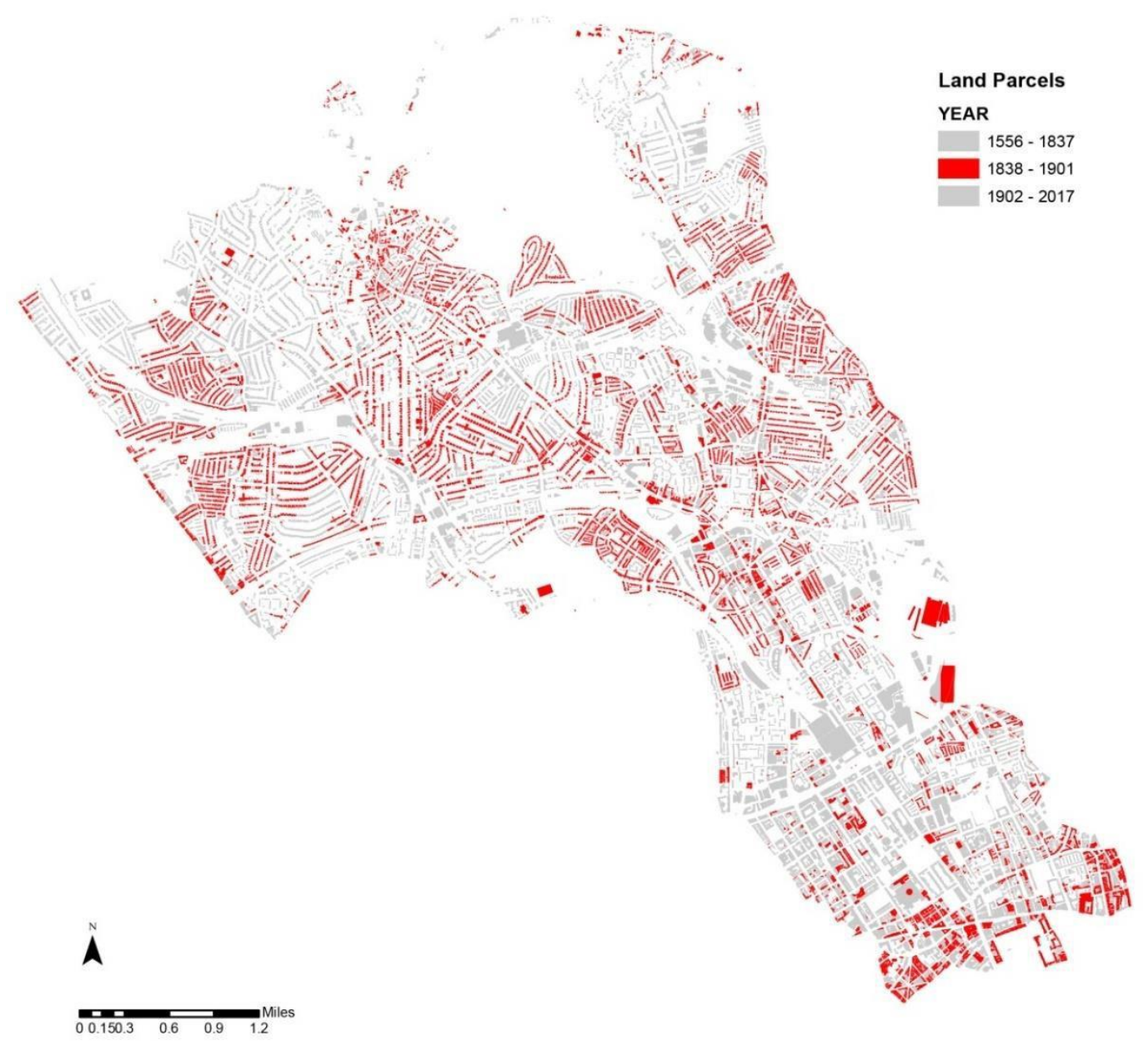

Figure 8. Map for the location of Victorian buildings in Camden (work in progress), being verified and using non-archived sources (based on Hudson, 2016). Reproduced courtesy of Ordnance Survey, OS MasterMap Data. 


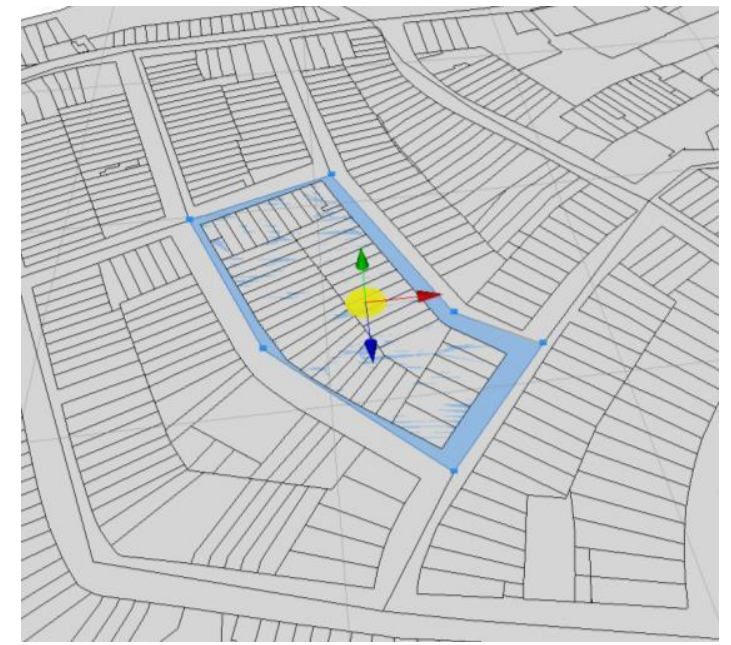

a.

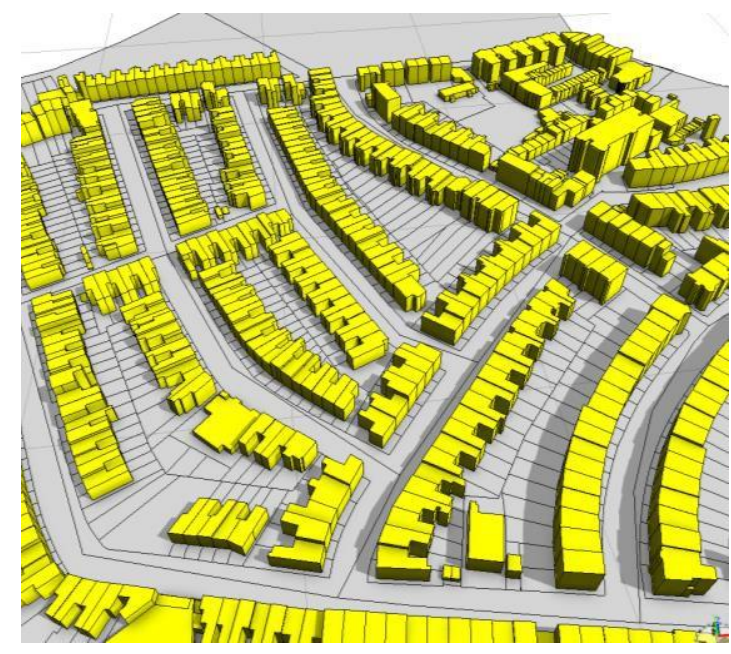

c.

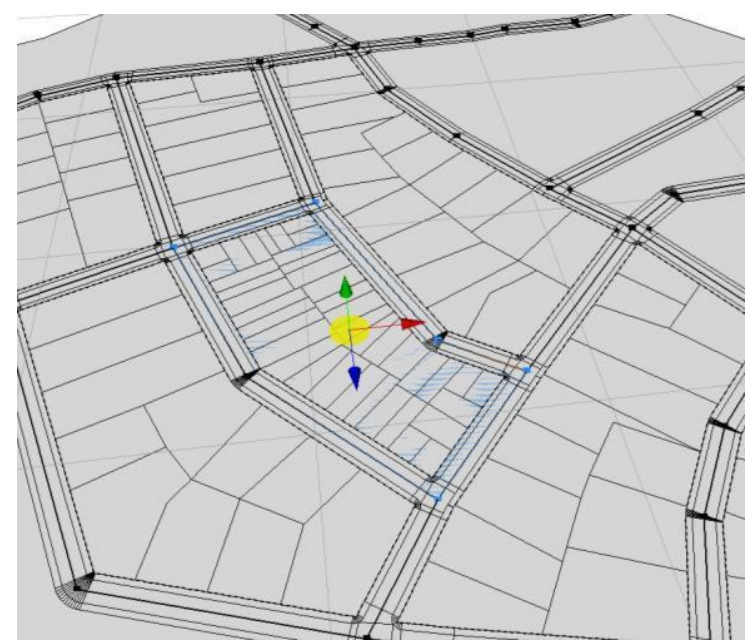

b.

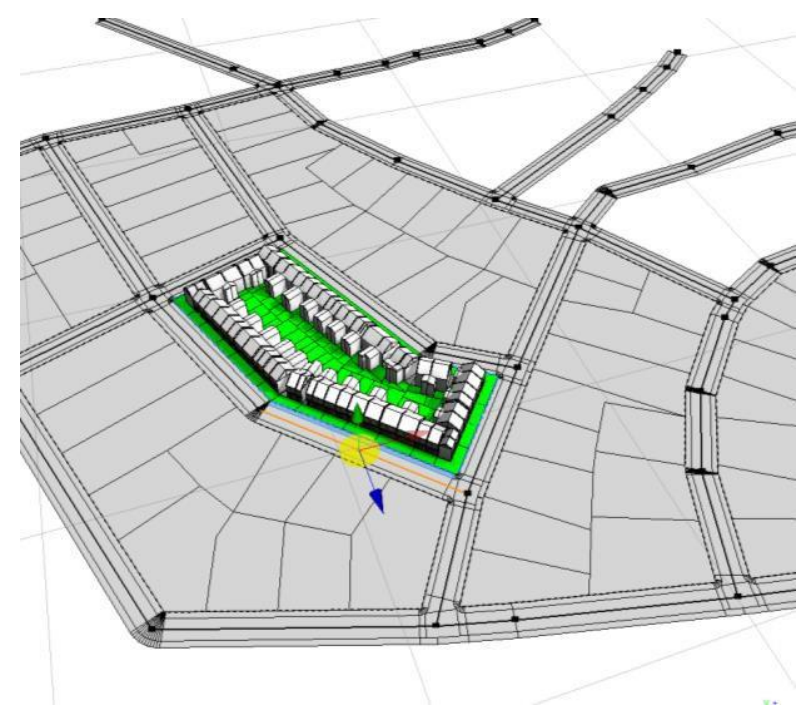

d.

Figure 9. Victorian block in Camden, (a) imported data from Land Map UK, create static shapes. (b) Generated block using road network data from OSM using statistics can produce dynamic geometries. (c) 3D extruded volumes according to building heights, using Edina footprints. (d) Generated Victorian footprints and buildings using road network and building types. 


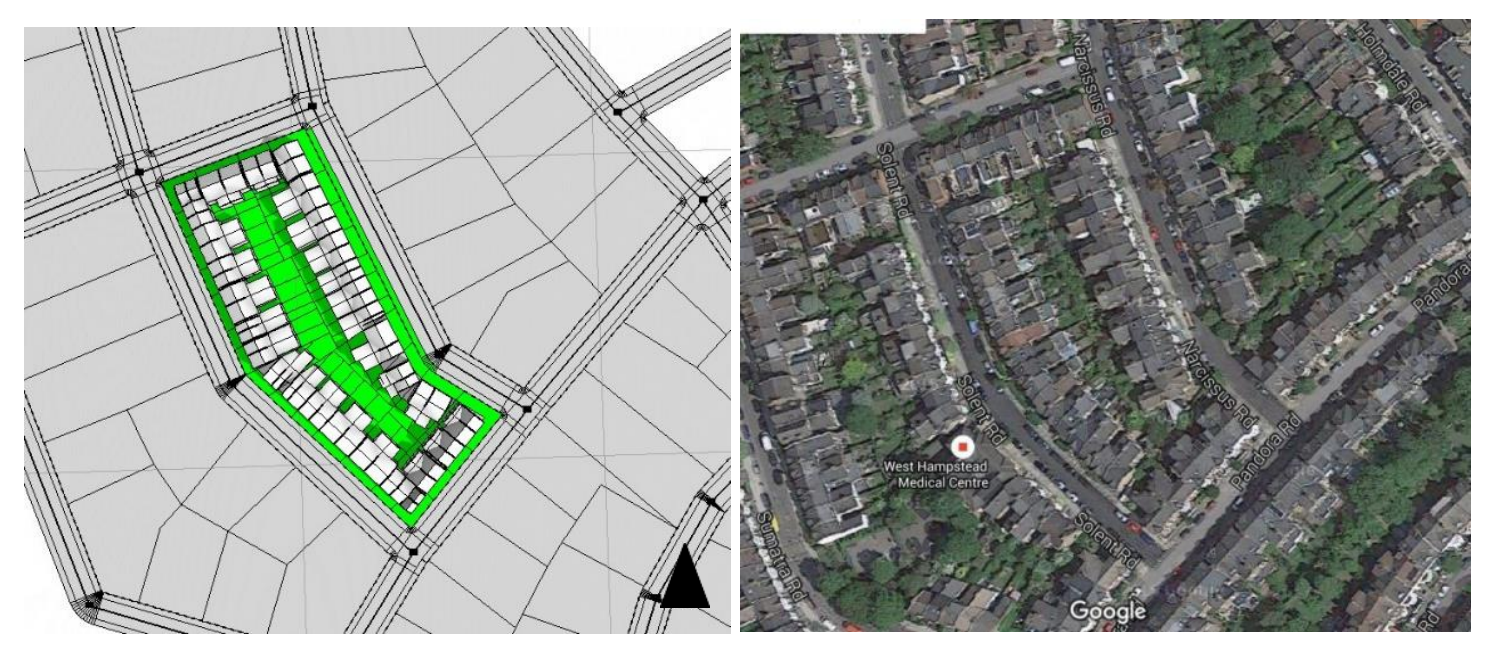

Figure 10. Comparison between a procedurally generated block and the actual areal imagery from Camden as captured in 2016. 


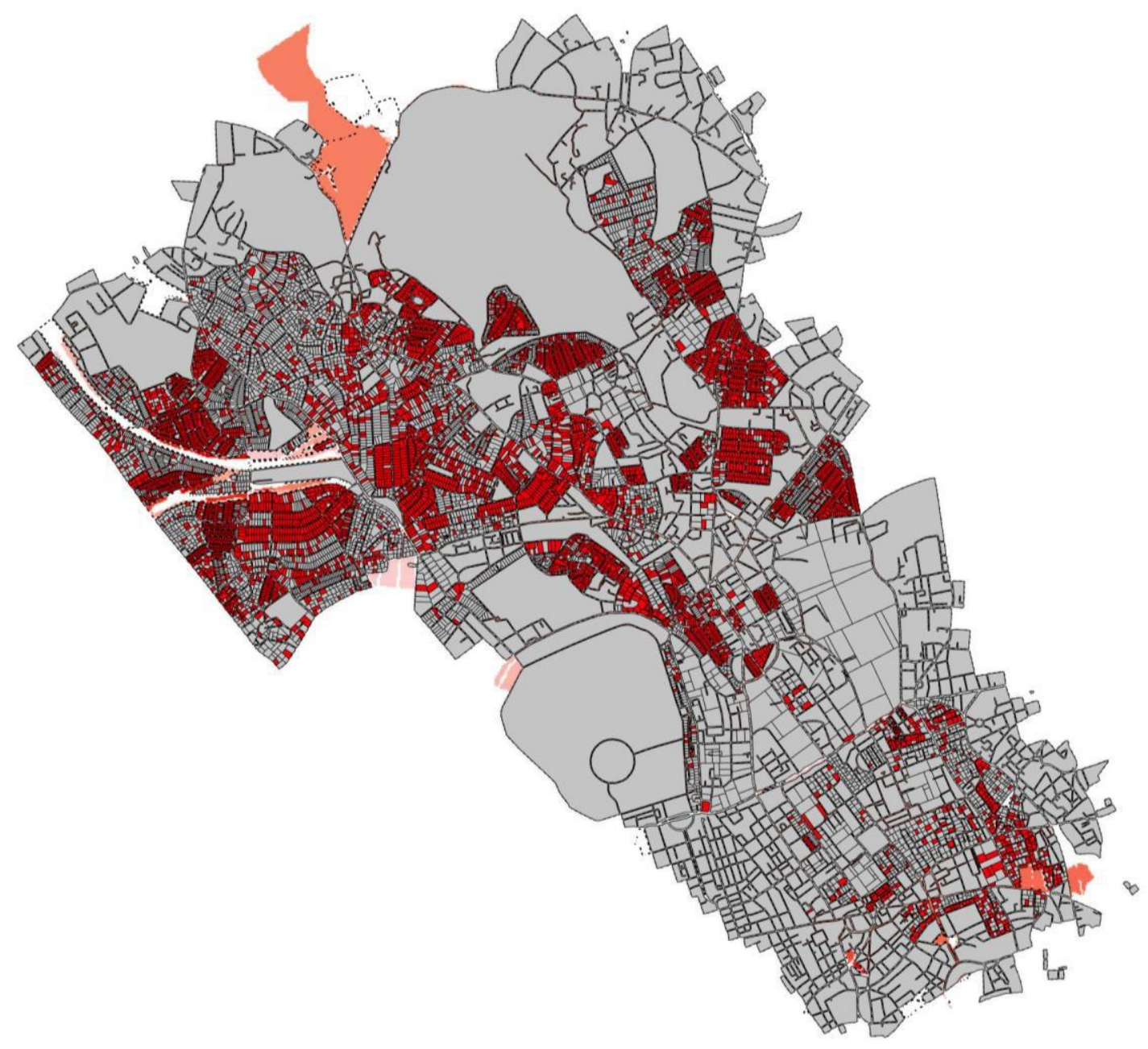

$3 \mathrm{~s}$

Figure 11. Locations of Victorian parcels, as allocated in procedural zones in Camden using the statistical approach in the environment of CityEngine. 

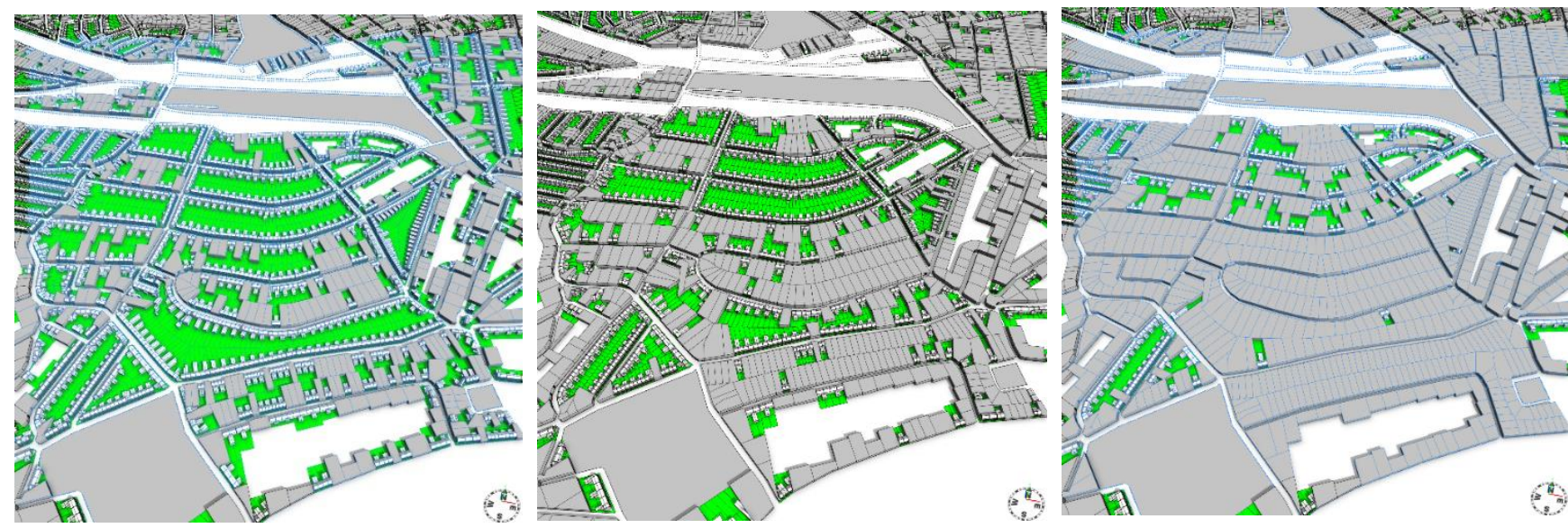

Figure 12. Neighbourhood in Camden with 90\% preserved Victorian buildings, $50 \%$ and $10 \%$ respectively. Plots with demolished or other buildings appear as grey. 